\title{
The Effect of Ageing on Cytochrome P450 Enzymes: Consequences for Drug Biotransformation in the Elderly
}

\author{
V. Wauthier, R.K. Verbeeck and P. Buc Calderon* \\ Unité PMNT, Ecole de Pharmacie, Université catholique de Louvain. 73, avenue E. Mounier, 1200 Bruxelles, \\ Belgium
}

\begin{abstract}
Ageing is an aggravating factor leading to alterations in the biotransformation of drugs, and therefore their therapeutic efficacy and safety. In this review we discuss the influence of ageing on drug metabolizing enzymes in male Wistar rats. We report that drug metabolizing enzymes can be affected by ageing either by post-translational modifications or by transcriptional modifications. The post-translational modifications could be due to an increase of oxidative stress during ageing. Although it is now well established that transcriptional modifications are due to a change in the GH secretion profile in senescent rats, the intracellular mechanisms underlying these modifications are still unclear. In addition to the strong decrease in the activity of the main CYPs of male rats, we discuss the potential consequences on human drug metabolism in the elderly.
\end{abstract}

Key words: Ageing, cytochrome P450, drug metabolism, growth hormone.

\section{INTRODUCTION}

The demographic structure of the population is changing very fast towards a much older population, as a consequence of a sharp increase in the life expectancy and a significant decrease of the average fecundity as well. Indeed, in Europe the percentage of elderly (population aged 65 and over) was around $16 \%$ in 2000 , and is expected to be $24 \%$ in 2030 (National Institute on aging. http://www.nia.nih.gov/).

Due to the markedly higher incidence of disease with age ( $80 \%$ of the elderly have at least one chronic disease), the elderly are the most medicated segment of the population taking approximately three times more medications as compared to younger individuals. In addition, they usually require multiple medications (polypharmacy) [1-3]. Finally, ageing is accompanied by marked changes in the physiology of many organs which, in turn, affect pharmacokinetics and pharmacodynamics [4]. All these factors contribute to the higher incidence of drug-drug interactions and increase the risk of adverse drug effects in the elderly [5-7]. Indeed, about $10 \%$ of all hospital admissions in the elderly are related to adverse drug reactions [8-10].

Pharmacotherapy for elderly patients is a major challenge both for the health professional (increased sensitivity to adverse reactions, enhanced risk of drug-drug interactions, etc.), and for the social security system which carries most of the financial burden of drug treatment [11,12]. Given the increase in life expectancy, the substantial increase in the number of elderly in the population, and the escalating costs of health care, there is great interest in learning more about the risks of toxic reactions to drugs associated with ageing.

Since significant pharmacokinetic changes occur in the elderly [4], it is of vital importance to appropriately adjust the normal dosage regimen in elderly patients to account for

*Address correspondence to this author at the Unité PMNT, Ecole de Pharmacie, Université catholique de Louvain. 73, avenue E. Mounier, 1200 Bruxelles, Belgium; E-mail: calderon@pmnt.ucl.ac.be these age-related changes. A better understanding of the underlying mechanisms of age-related changes on drug metabolizing enzyme activities is necessary to improve pharmacotherapy and, in turn, increase efficacy and decrease toxicity of treatment in the elderly.

\section{DRUG BIOTRANSFORMATION AND CYTO- CHROME P450}

Biotransformation reactions consist in the conversion of lipophilic drugs into more hydrophilic metabolites which, usually, are readily excreted in urine and/or bile. These metabolic transformations can be divided into phase I and phase II reactions. Phase I reactions are mainly catalysed by the enzymes of the cytochrome P450 system.

The cytochrome P450 (CYP450) enzyme system consists of a superfamily of haemoproteins that carry out oxidative, peroxidative and reductive metabolic transformations of a plethora of exogenous compounds (alcohols, aromatic organic compounds, including many environmental pollutants and natural plant products), endogenous compounds (steroids, bile acids, fatty acids, leukotrienes, prostaglandins and biogenic amines) and therapeutic agents. They are the principal enzymes that catalyse the metabolic transformation of foreign compounds and are also responsible for the metabolic activation of chemical carcinogens. Regarding the diversity of substrates that are metabolized, CYP450 enzymes (CYPs) are considered as the most versatile biological catalysts known [13].

The enzymes of the cytochrome P450 system can be found in almost all living organisms such as bacteria, yeasts, plants and animals. Their tissue distribution is almost ubiquitous, but the expression of CYPs involved in the metabolism of xenobiotics is highest in the liver. Lower levels of selected CYPs are also found in extrahepatic tissues such as gastrointestinal tract (intestinal mucosa), lungs, kidneys, skin, olfactory epithelia, and even in the central nervous system [14]. 
In humans, 18 families of cytochrome P450 genes and 43 subfamilies have been identified (http://drnelson. utmem.edu/). Four of the P450 gene families (families CYPs 1-4) code for liver-expressed enzymes that metabolize foreign compounds, therapeutic agents and endogenous lipophilic substrates. (Table 1) shows the various human and rat CYP450 enzymes belonging to these families. CYPs belonging to the other mammalian CYP gene families typically do not metabolize foreign chemicals. Rather, they metabolize endogenous substrates along physiologically important pathways: CYP families 5 and 8 are important for thromboxane and prostacyclin biosynthesis; CYP families $11,17,19$, and 21 catalyze hydroxylation reactions required for steroid hormone biosynthesis from cholesterol. CYP families 7, 24, 27, and 51 catalyze hydroxylations required for the biosynthesis of bile acids, activated vitamin D3, and cholesterol, and CYP26 catalyzes the hydroxylation of retinoic acid, a step that may be important during development [15].

The reactions catalyzed by CYPs involve mainly oxidation reactions but, under anaerobic conditions, they can also catalyse reduction reactions [16]. The oxidation of a substrate is represented by the overall following reaction:

$$
\mathrm{RH}+\mathrm{O}_{2}+\mathrm{NADPH}+\mathrm{H}^{+} \rightarrow \mathrm{ROH}+\mathrm{H}_{2} \mathrm{O}+\mathrm{NADP}+
$$

To be functional, CYPs must be part of multicomponent electron transfer chains, called P450-containing monooxygenase systems or mixed-function oxygenases (MFO). There are two different kinds of electron transfer chains for CYPs: the NADPH cytochrome P450 reductase, and the NADH cytochrome b5 reductase.

\section{EFFECT OF AGEING ON DRUG METABOLISM AND CYPS IN HUMANS}

\section{a. The Effect of Age on Hepatic Drug Clearance}

Age-related changes in pharmacokinetics are probably multi-factorial. Indeed, ageing is accompanied by changes in the physiology of many organs such as a gradual loss of the efficiency of the heart as a pump, a marked reduction in the capacity of the kidneys to remove certain substances from the circulation, a reduced elasticity and capacity of the lungs leading to decreased oxygenation of blood, etc [17], as well as in their constituent cells which may, in turn, affect processes determining drug disposition [18-21].

Although the metabolism of certain drugs remains unchanged during ageing, the elimination of most of drugs with blood-flow limited hepatic clearance is reduced in the elderly [4,10,22-25]. However, the reasons why hepatic clearance is reduced with age have not been satisfactorily elucidated and remain, to some extent, controversial. Several studies implicate decreased liver volume and blood flow as critical factors contributing to the age-related declines in clearance of several model drugs [10,26-29]. However, the influence of age in humans on the intrinsic activities of drug metabolizing enzymes is still largely unknown.

Since ageing is an aggravating factor that may lead to an impairment in the biotransformation of drugs, and therefore in their therapeutic efficacy and safety, a better understanding of the underlying mechanisms of age-related changes in drug metabolizing enzyme activities is necessary to improve the efficacy and safety of pharmacotherapy in the elderly.

\section{b. Effect of Ageing on the Cytochrome P450 Enzymes}

Investigations on the influence of ageing on phase I enzymes in humans have reported conflicting results. Indeed, a study conducted in 54 liver samples from healthy donors from 9 to 89 years did not show changes in either microsomal protein content, total P450 nor NADPH cytochrome P450 reductase activity with age [30]. By contrast, another study carried out in 226 subjects with histopathologic changes of the liver revealed a significant decrease of $32 \%$ in total cytochrome P450 content of liver biopsy samples and a decrease of $29 \%$ of the in vivo

Table 1. Human and Rat CYP Belonging to the Families 1-4 (www. drnelson.utmem.edu)

\begin{tabular}{|c|c|c|c|}
\hline & & HUMAN & RAT \\
\hline CYP1 & $\begin{array}{l}\text { CYP1A } \\
\text { CYP1B }\end{array}$ & $\begin{array}{c}\text { CYP1A1, 1A2 } \\
\text { CYP1B1 }\end{array}$ & $\begin{array}{c}\text { CYP1A1, 1A2 } \\
\text { CYP1B1 }\end{array}$ \\
\hline CYP2 & $\begin{array}{l}\text { CYP2A } \\
\text { CYP2B } \\
\text { CYP2C } \\
\text { CYP2D } \\
\text { CYP2E } \\
\text { CYP2F } \\
\text { CYP2G } \\
\text { CYP2J } \\
\text { CYP2R } \\
\text { CYP2S } \\
\text { CYP2U } \\
\text { CYP2W }\end{array}$ & $\begin{array}{c}\text { CYP2A6, 2A7, 2A1, 2A18 } \\
\text { CYP2B6, 2B7 } \\
\text { CYP2C8, 2C9, 2C18, 2C19 } \\
\text { CYP2D6, 2D7, 2D18 } \\
\text { CYP2E1 } \\
\text { CYP2F1 } \\
\text { CYP2J2 } \\
\text { CYP2R1 } \\
\text { CYP2S1 } \\
\text { CYP2U1 } \\
\text { CYP2W1 }\end{array}$ & $\begin{array}{c}\text { CYP2A2, 2A3 } \\
\text { CYP2B1, 2B2, 2B3 } \\
\text { CYP2C6, 2C7, 2C11, 2C12, 2C13, 2C22, 2C23 } \\
\text { CYP2D2, 2D3, 2D4, 2D18, 2D5 } \\
\text { CYP2E1 } \\
\text { CYP2F4 } \\
\text { CYP2G1 } \\
\text { CYP2J3 } \\
\text { CYP2R1 } \\
\text { CYP2S1 }\end{array}$ \\
\hline CYP3 & CYP3A & CYP3A4, 3A5, 3A7 & CYP3A1, 3A2, 3A9, 3A18, 3A23 \\
\hline CYP4 & $\begin{array}{l}\text { CYP4A } \\
\text { CYP4B } \\
\text { CYP4F } \\
\text { CYP4V } \\
\text { CYP4X }\end{array}$ & $\begin{array}{c}\text { CYP4A11, 4A20 } \\
\text { CYP4B1 } \\
\text { CYP4F2, 4F3, 4F8, 4F11, 4F12, 4F22 } \\
\text { CYP4V2 } \\
\text { CYP4X1 }\end{array}$ & $\begin{array}{c}\text { CYP4A1, 4A2, 4A3, 4A8 } \\
\text { CYP4B1 } \\
\text { CYP4F1, 4F4, 4F5, 4F6, 4F19 }\end{array}$ \\
\hline
\end{tabular}


antipyrine clearance in subjects $>70$ years as compared to young adults [23].

Antipyrine has been frequently used in the past to assess in vivo phase I drug metabolism activity in healthy subjects and patients. However, antipyrine is not a good probe to identify the loss in the activity of one particular enzyme because it is metabolized by multiple CYPs (CYP3A4, 1A2, 2B6, 2C18 and others). To assess the activity of individual CYPs, the use of specific enzyme substrates is needed. Regarding the hepatic content of individual CYP450 enzymes in humans as a function of age, results are also quite controversial. Indeed, Shimada et al. (1994) did not observe any change in the content of specific CYP450 isoenzymes as a function of age in livers from 60 subjects between 12 and 73 years [31]. By contrast, another study carried out in 71 individuals showed that, while the content of some isoforms such as CYP1A2 and CYP2C remains constant, total cytochrome P450, CYP2E1 and CYP3A contents as well as the NADPH reductase activity decrease with increasing age [32]. Studying the effect of age on the activity of individual CYP450 enzymes is difficult because a drug may be metabolized by more than one isozyme. However, the results obtained with specific substrates may be summarized as follows: the rate of metabolism may be decreased for substrates of CYP1A2 and CYP2C19, decreased or unchanged for substrates of CYP3A4, 2A and 2C9 and unchanged for substrates of CYP2D6 [25,33]. The reasons of such discrepancies in human studies are unknown.

Hepatic metabolism and its relationship with ageing is difficult to understand due to a host of factors that contribute to the enormous variability in hepatic drug biotransformation. Indeed, a high intersubject variability in CYP activity is also observed in a normal, healthy, well-defined population of subjects of similar age. Considerable variability is expected as a result of the following factors: concurrent drug use (including alcohol, drugs of abuse, and caffeine), diseases, environmental exposure (including smoking), gender, genetic differences, liver mass and nutritional intake. As a result, it is not surprising that it is extremely difficult to clearly identify age as a separate variable among all these other factors. For example, smoking influences the rate of metabolism of certain substances and could be a confounding factor in studies of drug metabolism. Given this variability, it is important to have large numbers of individuals in the study to acquire more representative data. Many studies were carried out on relatively small groups of individuals. This may explain, in part, why the majority of studies does not demonstrate an age difference in the rate of hepatic drug elimination. Moreover, from an ethical point of view, it is not easy to collect liver samples from relatively healthy subjects and therefore most of the in vitro results were obtained in subjects who underwent liver biopsy for some hepatic pathology.

\section{EFFECT OF AGEING ON CYPS IN RATS}

By carrying out drug metabolism experiments in laboratory animals many sources of variability can be excluded. In rodents, like in humans, a number of studies have described an age-related decline in the clearance of drugs that undergo biotransformation by the hepatic microsomal mono-oxygenases [34-38].

In 1968, Kato and Tanaka first reported a significant agerelated decline in the in vitro concentrations and/or activities of hepatic microsomal mono-oxygenases in male rats [39-

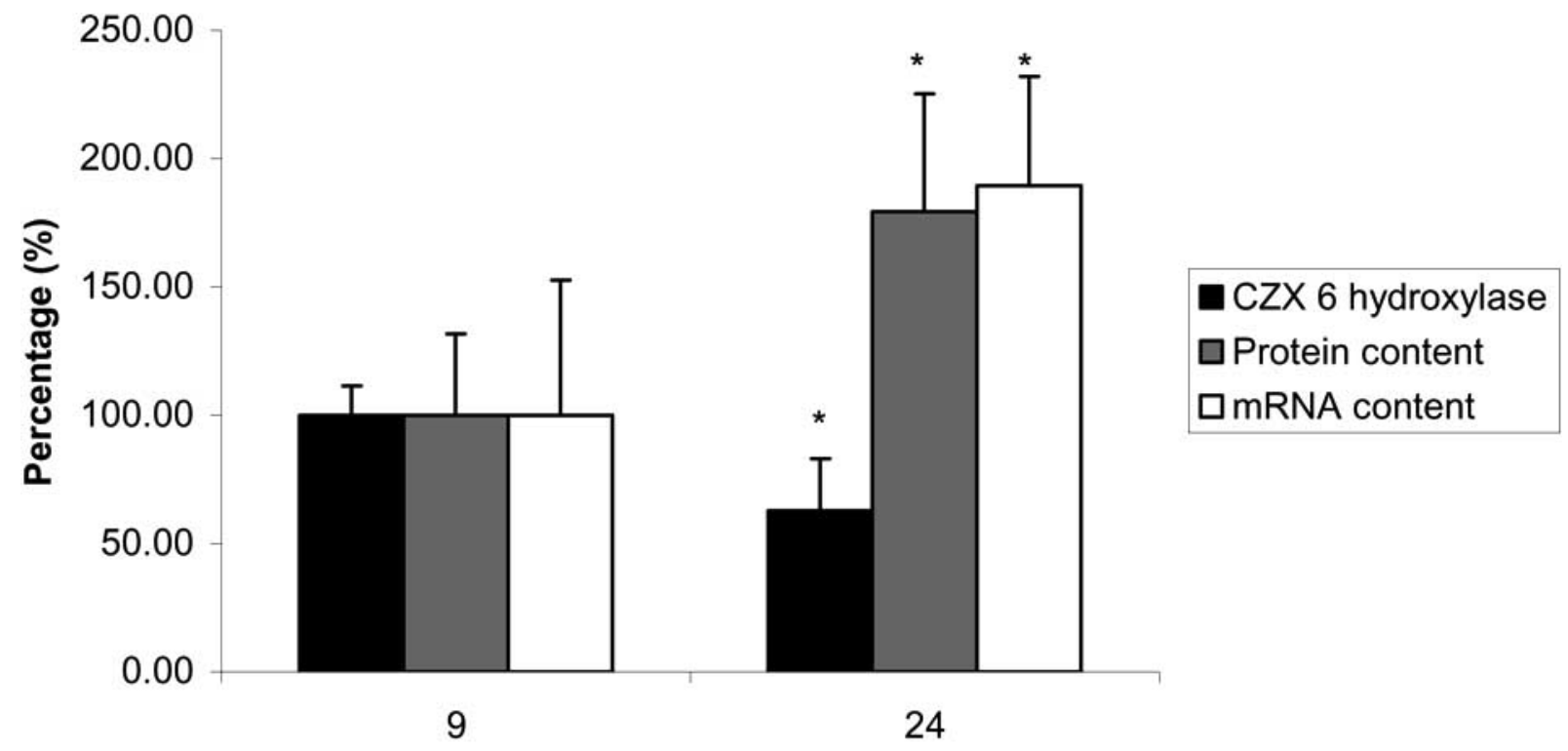

\section{Months}

Fig. (1). CYP2E1-mediated chlorzoxazone oxidation, CYP2E1 protein content and mRNA level in the liver of adult and senescent male rats. CYP2E1 activity was measured in liver microsomes prepared from adult and senescent male rats. 100\% of CYP2E1 activity corresponds to $5.5 \pm 0.6 \mathrm{nmol} / \mathrm{min} / \mathrm{mg}$ prot. The amount of CYP2E1 proteins was determined by Western blots. $100 \%$ of protein content corresponds to $1.9 \pm 0.6$ optical density units. The CYP2E1 mRNA content was assessed by RT-PCR. 100\% of CYP2E1 mRNA content (normalized to $\beta$-actin mRNA levels) corresponds to $0.7 \pm 0.4$ arbitrary units. Values represent the mean \pm SEM of 6 rats. (*) $\mathrm{p}<0.05$ as compared to rats 9 months old. 
47], but the age-related effect does not concern all enzymes of the cytochrome P450 system $[42,43,45]$.

In rats, a decrease in the metabolism of a number of drugs has been reported. For example, the in vitro metabolism of phenacetin [44], chlorzoxazone [47], triazolam [48], and midazolam [46], has been shown to be decreased by $60 \%, 37 \%, 50 \%$, and $55 \%$, respectively, in senescent rats.

Regarding the cause of these reduced drug metabolizing enzyme (DME) activities, 2 types of modifications (occurring during ageing) have been proposed: posttranslational $[45,47,49]$ and transcriptional modifications $[42,43,46]$.

\section{AGE-RELATED CHANGE OF RAT CYPS ACTIVITIES OCCURRING AT THE POST- TRANSLATIONAL LEVEL}

Post-translational modifications have been evoked to explain the unusual results regarding the effect of ageing on CYP2E1 activity in male rats [47]. Indeed, the CYP2E1related activity (chlorzoxazone oxidation) is reduced by $37 \%$ in senescent rats, while both CYP2E1 protein and mRNA levels are increased by approximately 80 and $65 \%$, respectively (Fig. 1). Since CYP2E1 generates high levels of reactive oxygen species (ROS), this CYP isozyme is more susceptible than others to undergo oxidative injury. Therefore, the decreased CYP2E1 activity in senescent rats could be due to oxidative modifications occurring during ageing as shown by the increased lipid peroxidation [45,47]. However, the cause-effect relationship remains to be demonstrated. Such post-translational modifications have also been evoked to explain decreased activity of NADPH cytochrome P450 reductase activity [49] as well as the decreased activity of SULT1A1 [50] in senescent rats.

The constitutive level of CYP2E1 is transcriptionally regulated by liver-enriched transcription factors. Among them, a role of HNF1 $\alpha$ in the positive regulation of CYP2E1 has been shown both by in vitro transcription and

\section{Males}

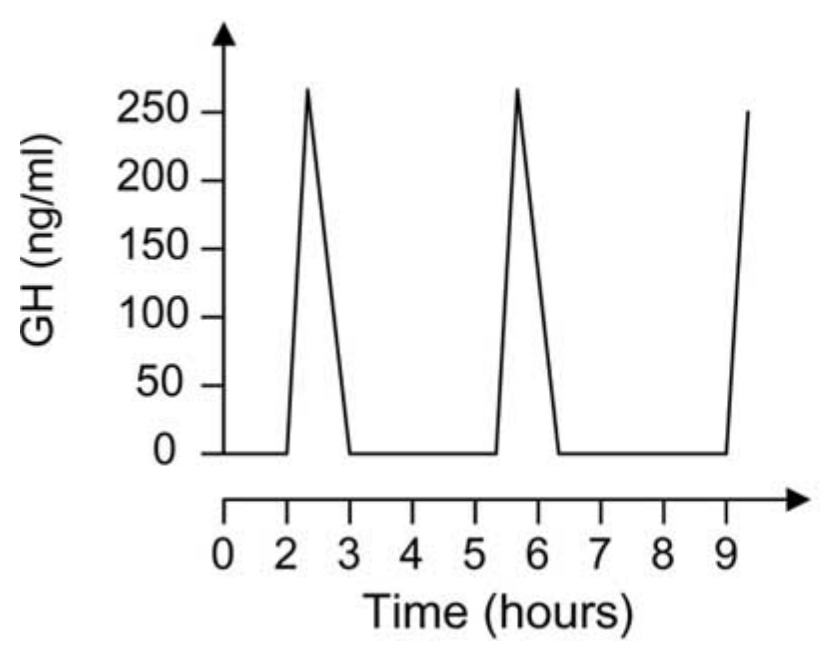

trans-activation studies [51] and by studies using HNF1 $\alpha$ deficient mice, where a drastic decrease of CYP2E1 expression was observed [52]. Since a strong increase (154 $\%)$ in the amount of HNF1 $\alpha$ mRNA is observed in senescent male rats [47], the increase of CYP2E1 expression in senescent rats may be related to the age-related increase of HNF1 $\alpha$.

\section{AGE-RELATED CHANGE OF RAT CYPS ACTIVITIES OCCURRING AT THE TRANSCRIP- TIONAL LEVEL}

\section{a. Growth Hormone (GH) Regulation of CYPs Expression}

Many studies in rats have demonstrated that the expression of CYPs is changed by experimental manipulation of the level of different hormones such as gonadal hormones, thyroid hormone, insulin, glucagon, glucocorticoïds and growth hormone $(\mathrm{GH})$. It is not surprising, therefore, that CYPs expression may be modified during development and ageing, is subject to sex-differences, and may be affected by conditions such as pregnancy, menstrual cycle, and pathologies with hormonal perturbations such as diabetes.

The activity of certain enzymes of the cytochrome P450 system are clearly sex-dependent. Their regulation is dependent on the growth hormone. Notable sex differences in the expression of a number of CYPs have been reported in rat [53], mouse [54] and human liver [55,56]. Nevertheless, rats have much more pronounced sex differences in drug metabolism, compared with mice and humans, and have, therefore, been used as a model to study mechanisms regulating this dimorphism [53].

Sex-dependent hepatic CYPs in the rat are generally divided into four groups: male-specific isoforms only found in male liver, female-specific isoforms only expressed in female liver, male-predominant CYPs found in both sexes but at higher levels in livers of males, and femalepredominant CYPs found in both sexes but at higher levels

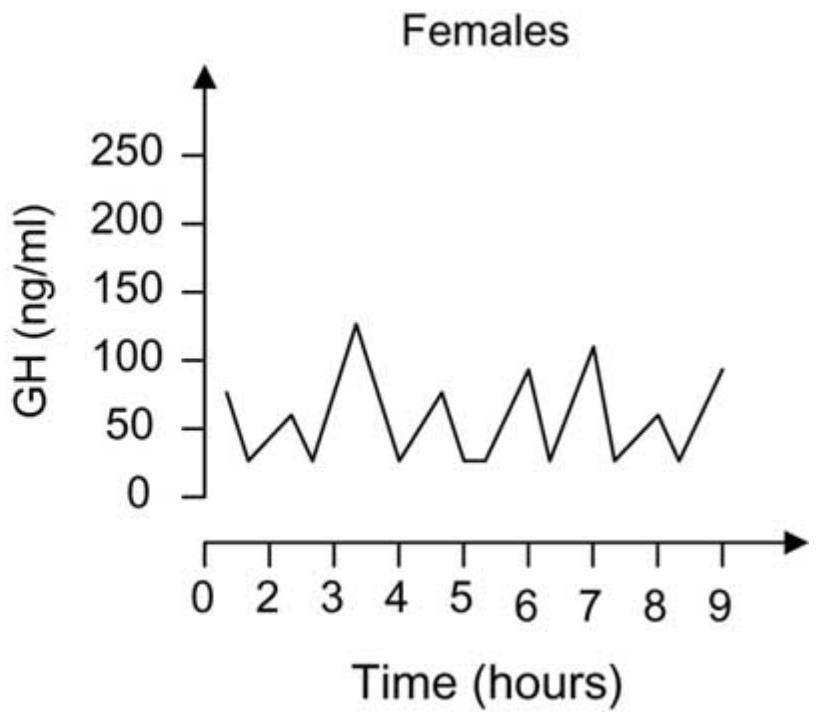

Fig. (2). Schematic representation of GH secretion patterns $(\mathrm{ng} / \mathrm{ml})$ in adult female and male rats. (adapted from [44]). 
Table 2. Sexually Differentiated CYPs in Rat Liver [14,64]

\begin{tabular}{|c|c|c|c|}
\hline Male specific isoforms & Female specific isoforms & Male predominant isoforms & Female predominant isoforms \\
\hline CYP2C11 & CYP2C12 & CYP3A18 & CYP3A9 \\
\hline CYP3A2 & & CYP3A23 & CYP1A2 \\
\hline CYP2A2 & & & CYP2A1 \\
\hline CYP2C13 & & & CYP2C7 \\
\hline CYP2C22 & & & CYP2E1 \\
\hline CYP4A2 & & & CYP2C6 \\
\hline
\end{tabular}

in liver of females (Table 2). For example, in rats, well characterized male-specific liver CYPs include CYP2C11 and CYP3A2. There is only one female-specific isoform in the rat, i.e. CYP2C12. Male predominant isoforms include, for example, CYP3A18 and CYP3A23, and female predominant isoforms include CYP3A9 and CYP2C6. This sexual dimorphism of cytochrome $\mathrm{P} 450$ enzymes is due to a differential profile of $\mathrm{GH}$ in male and female rats. Indeed, growth hormone, a polypeptide hormone produced by somatotroph cells of the anterior pituitary, is secreted into the circulation in a sexually dimorphic manner by the somatotroph cells of the anterior pituitary gland in many species, including rats, mice and humans [57]. The sexual dimorphism in the $\mathrm{GH}$ secretion profile is particularly pronounced in rats [53]. In the adult male rat, $\mathrm{GH}$ is secreted by the pituitary gland in a highly regular, pulsatile manner, with high peaks of hormone (200-300 ng GH/ml plasma) occurring every $3.5 \mathrm{~h}$, separated by periods during which $\mathrm{GH}$ levels are undetectable $(\leq 2 \mathrm{ng} / \mathrm{ml})$. By contrast, as shown in (Fig. 2), pituitary GH release in the adult female rat is more frequent and results in a near continuous presence of $\mathrm{GH}$ in the circulation at concentrations typically ranging from 15 to $40 \mathrm{ng} / \mathrm{ml}[43,57]$.

A key difference in male and female GH profiles in both rats and mice is the sustained interpulse interval of no detectable circulating $\mathrm{GH}$ that is characteristic for adult males. This GH free interval is required for the expression of male specific CYP genes and for suppressing the expression of genes normally restricted to females [58]. By contrast, nearly continuous $\mathrm{GH}$ exposure, a characteristic of female rats, induces the expression of liver-CYP genes that are typical for females [58]. Indeed, when the male-characteristic $\mathrm{GH}$-free interval is eliminated by treating male rats or mice with exogenous $\mathrm{GH}$, given as a continuous infusion over several days, the $\mathrm{GH}$ pulse-induced-expression of male specific genes is abolished and the expression of femalespecific genes is dramatically induced [43].

The sex-dependent expression of CYP genes is developmentally regulated by $\mathrm{GH}$ at the transcription level in the liver $[59,60]$. Sex-dependent differences in plasma GH profiles first emerge at puberty but are set, and ultimately regulated, by gonadal steroid imprinting during the neonatal period [61,62]. In rats, exposure to androgens during the first three days of life is sufficient to imprint the malespecific pituitary $\mathrm{GH}$ secretory pattern that emerges at puberty $[63,64]$.

In prepubertal and pubertal rats, the secretion of $\mathrm{GH}$ is also episodic. Indeed, in 22 day-old rats, there were distinct periods of increased plasma $\mathrm{GH}$ levels indicating episodic

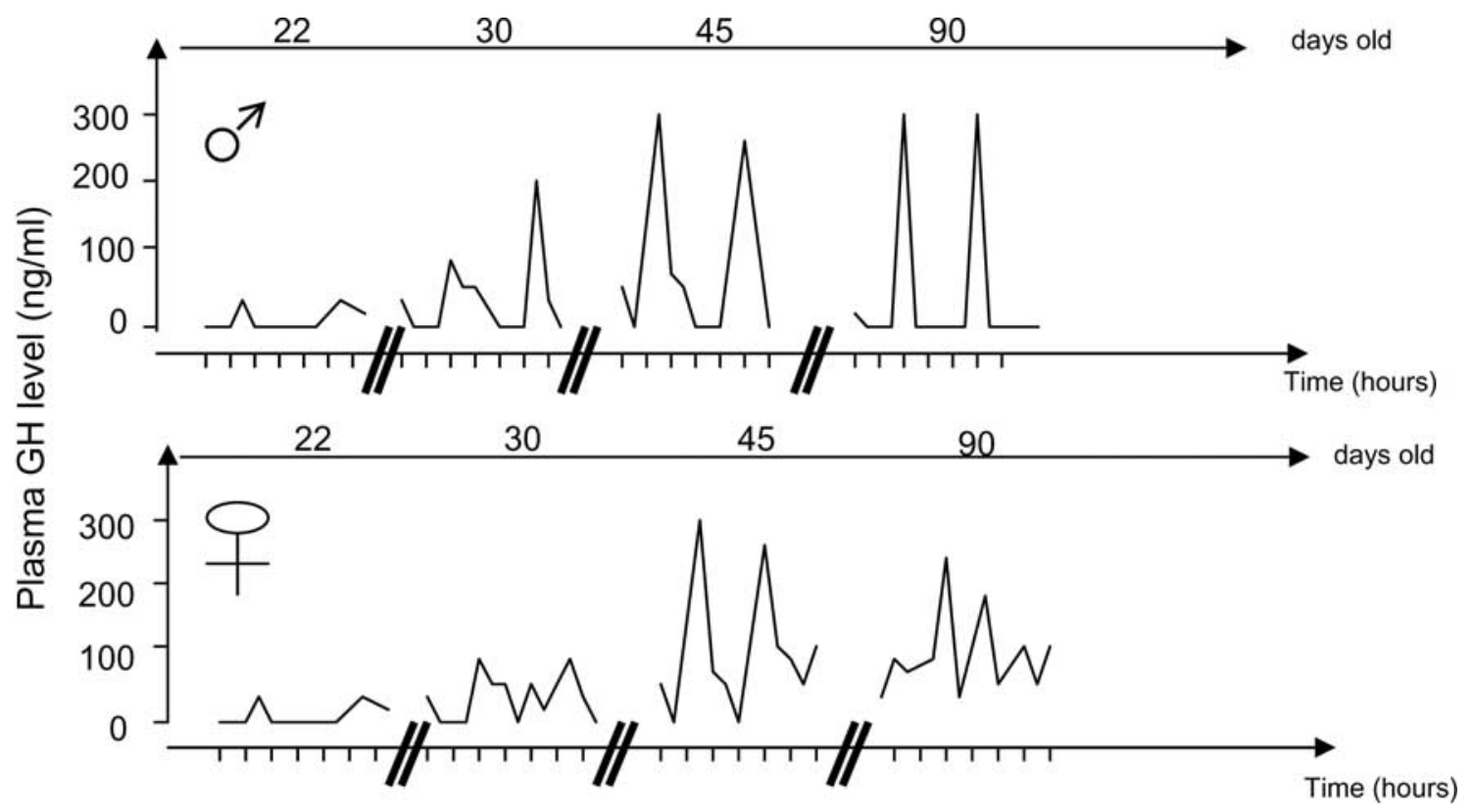

Fig. (3). Schematic representative 6-h secretory profile in pre-pubertal female (lower panel) and male (upper panel) rats at the age of $22,30,45$, and 90 days (adapted from [67]). 
secretion of GH (Fig. 3). However, the highest peak levels are significantly lower than those observed in older animals. At this age, no difference in GH secretion pattern can be observed between males and females. The sex difference appears as early as 25-30 days of age, that is before vaginal opening in female rats [65]. In 30-day-old females, the GH peak levels are increased but remain, however, significantly lower than those in males. In 45-day-old females (after vaginal opening) GH peak levels reach $200-300 \mathrm{ng} / \mathrm{ml}$ and occur at more frequent intervals than in males. The $\mathrm{GH}$ levels between peaks are often higher than $5 \mathrm{ng} / \mathrm{ml}$. In 90day-old male and female rats, puberty is achieved and their GH secretory patterns show a clear sex difference as previously described.

\section{The Male Specific Isoforms (CYP2C11 and CYP3A2)}

After birth, the levels of CYP2C11 expression are low in both male and female rats but, as shown in (Fig. 4), its expression is increased by more than 30 -fold between 4-6 weeks in males but not in females [41,63]. Thus, the development pattern of CYP2C11 expression in the liver coincides with the sexually differentiated pattern of $\mathrm{GH}$ secretion.

In male rats, CYP2C11 represents more than $50 \%$ of the total hepatic cytochrome P450 enzymes [41,63]. CYP2C11 is a "class I" male-specific liver CYP gene, i.e. one whose expression is obligatorily dependent on the repeated stimulation by male plasma GH pulses [64]. In hypophysectomized rats, CYP2C11 expression is reduced to $30 \%$ of the normal level $[41,65]$.

Unlike CYP2C11, CYP3A2 activity is constitutively present at low levels and has increased significantly by one week of age in both sexes (Fig. 4). At puberty, CYP3A2 expression declines in female rats while it continues to be expressed in male rats [64]. The sex specificity of this CYP thus reflects a developmental repression which only occurs in females. Although CYP3A2 is also a male specific isoform, it belongs to a second, distinct class of malespecific CYPs. In contrast to the class I male specific isoforms, expression of the class II CYPs remains at a high level in hypophysectomized rat liver and therefore, does not require stimulation by plasma $\mathrm{GH}$ pulses [66].

\section{The Female Specific (CYP2C12)}

CYP2C12 is induced during development in female rats reaching adult levels around 7-8 weeks (Fig. 4). Although CYP2C12 is female specific in adult rat liver, it is also expressed at significant levels in 4-week-old males $[42,63]$.

CYP2C12 represents around $40 \%$ of the total CYPs in the female rat liver [67]. Its expression requires exposure to the female pattern of continuous growth hormone secretion. The absence of growth hormone (i.e., hypophysectomy) or exposure to the male profile of episodic secretion completely suppresses CYP2C12 expression [65].

\section{b. Effect of Ageing on GH Secretion Profile and CYPs Activities}

As mentioned previously the age-related decreased activity of certain CYPs can be due to either posttranslational or transcriptional changes occurring during ageing. Indeed, changes in the transcription of sex-dependent CYP genes have been reported $[42,43,46]$. More specifically, there is a demasculinization of the cytochrome P450 characterized by a decrease of male specific CYP gene expression during ageing $[42,43,46]$. For example, in senescent male rats, the protein levels of CYP2C11 (Fig. 5)

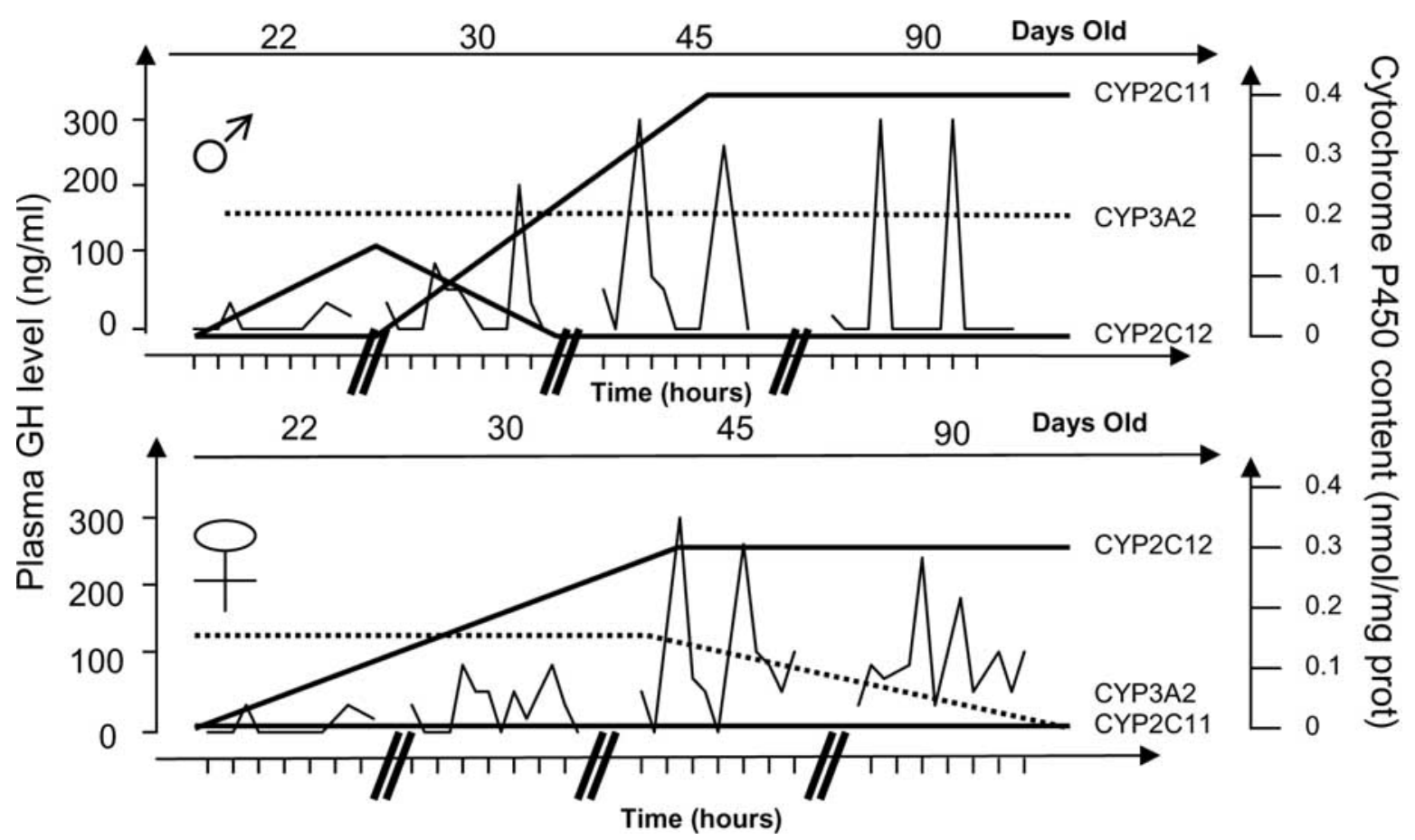

Fig. (4). Schematic representation of the relationship between the age-related CYP expression and the age-related changes of the GH secretion profile. The ontogenic studies show that the development pattern of sex specific CYPs expression in the liver coincides with the sexual differentiated pattern of GH secretion (adapted from [64,67]). 


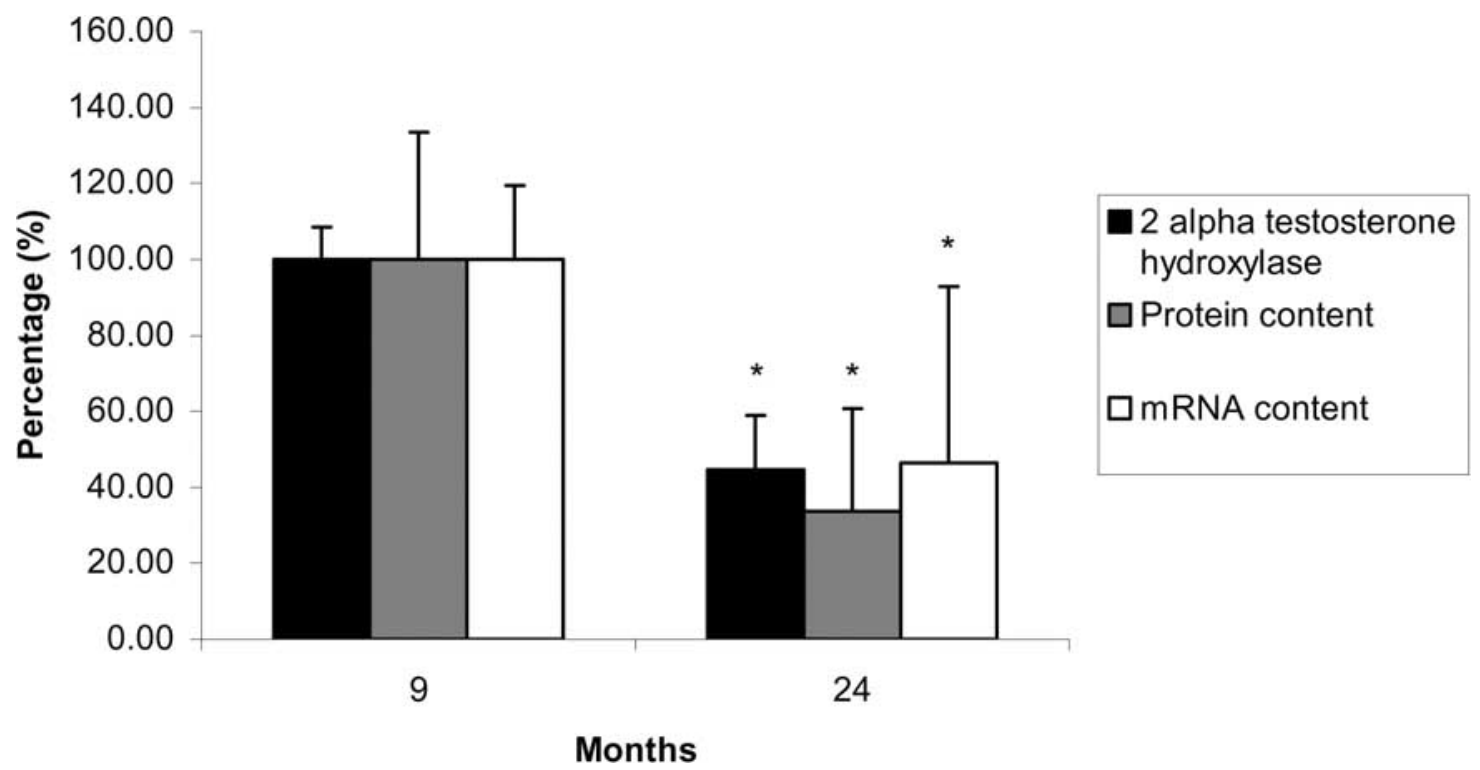

Fig. (5). CYP2C11-mediated testosterone $2 \alpha$ hydroxylation, CYP2C11 protein content and mRNA level in the liver of adult and senescent male rats. The CYP2C11 activity was measured in liver microsomes. $100 \%$ of CYP2C11 activity corresponds to $1.1 \pm 0.1$ $\mathrm{nmol} / \mathrm{min} / \mathrm{mg}$ prot. The content of CYP2C11 protein was measured by immunoblotting. $100 \%$ of protein content corresponds to $6.1 \pm$ 2.0 optical density units. The level of CYP2C11 mRNA was evaluated by RT-PCR. $100 \%$ of mRNA level (normalized to $\beta$-actin mRNA levels) corresponds to $2.2 \pm 0.4$ arbitrary units. Values represent the mean \pm SEM of 6 rats. $(*)$ p $<0.05$ as compared to rats 9 months old.

and CYP3A2 (Fig. 6), two major male specific isoforms, are decreased by about $85 \%$ and $65 \%$ respectively [46]. In addition to the demasculinization, a feminization of the hepatic CYP450 has also been observed $[42,43]$. Indeed, the CYP2C12 gene, only expressed in female rats, has been shown to be induced in the liver of senescent male rats (Fig. 7).
The first study reporting a demasculinization of cytochrome $\mathrm{P} 450$ in senescent rats, attributed this phenomenon to the decrease of testosterone level during ageing [42]. However, other authors have recently shown that the demasculinization and feminization of CYP450 in senescent male rats is due to changes of the typical male $\mathrm{GH}$ secretion profile [43]. Indeed, as shown in (Fig. 8) (upper

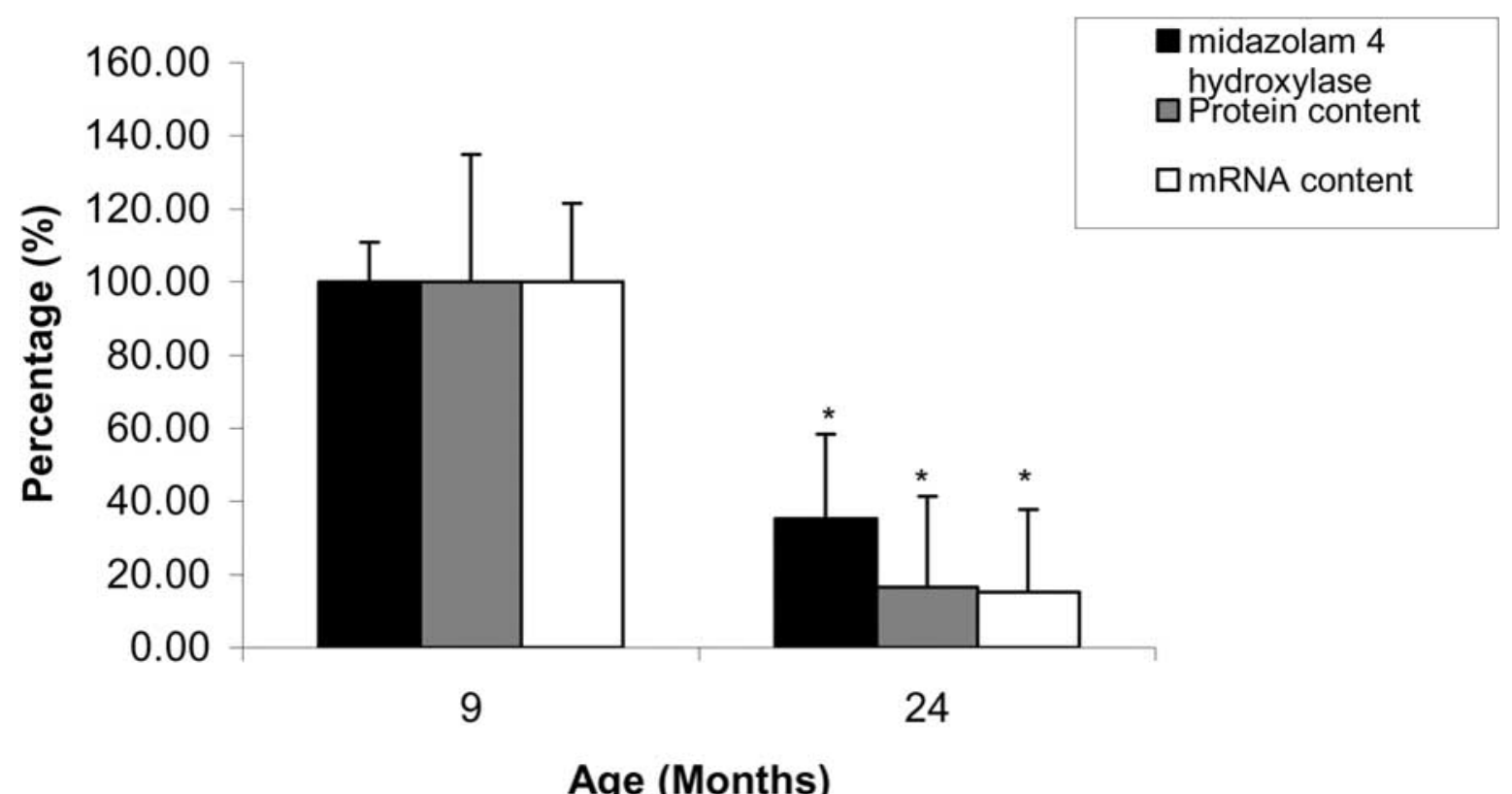

Fig. (6). CYP3A-mediated midazolam oxidation, CYP3A2 protein content and mRNA level in the liver of adult and senescent male rats. CYP3A2 activity was measured in liver microsomes. $100 \%$ CYP3A2 activity corresponds to $1.4 \pm 0.1 \mathrm{nmol} / \mathrm{min} / \mathrm{mg} \mathrm{prot}$. The content of CYP3A2 protein was assessed by immunoblotting. $100 \%$ of protein content corresponds to $3.1 \pm 1.0$ optical density units. The level of CYP3A2 mRNA was evaluated by RT-PCR. 100\% of mRNA level (normalized to $\beta$-actin mRNA levels) corresponds to 0.8 \pm 0.2 arbitrary units. Values represent means \pm ESM for $4-6$ rats. $(*) \mathrm{p}<0.05$ as compared to rats 9 months old. 


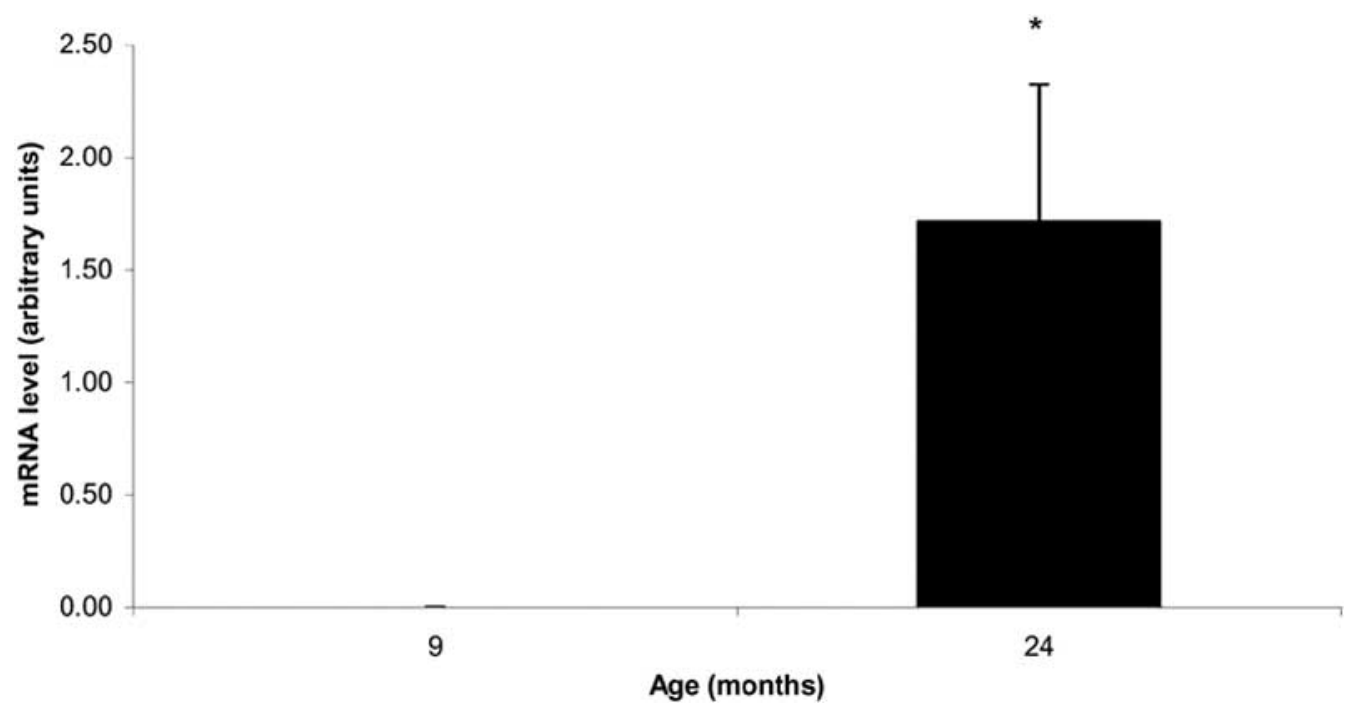

Fig. (7). CYP2C12 mRNA levels in the liver of adult and senescent male rats. The level of CYP2C12 mRNA was evaluated by RT-PCR. Values are expressed as arbitrary units (obtained by densitometry) after normalization to $\beta$-actin mRNA expression levels. (*) $\mathrm{p}<0.05$ as compared to rats 9 months old.

$\underline{3 \text { months }}$

$\underline{24 \text { months }}$

\section{Male rats:}

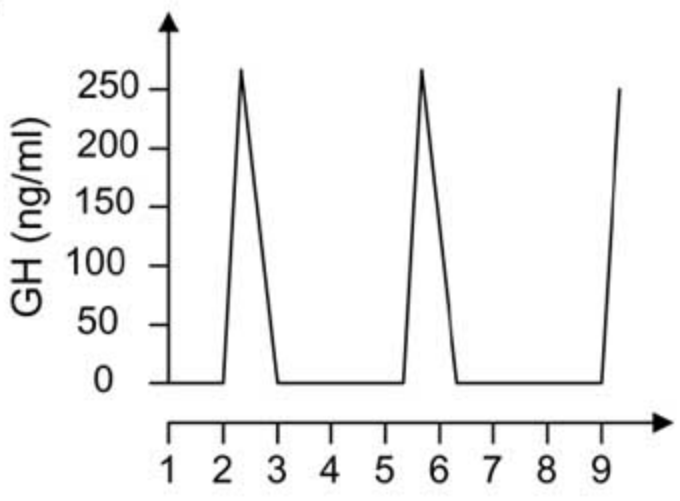

Time (hours)

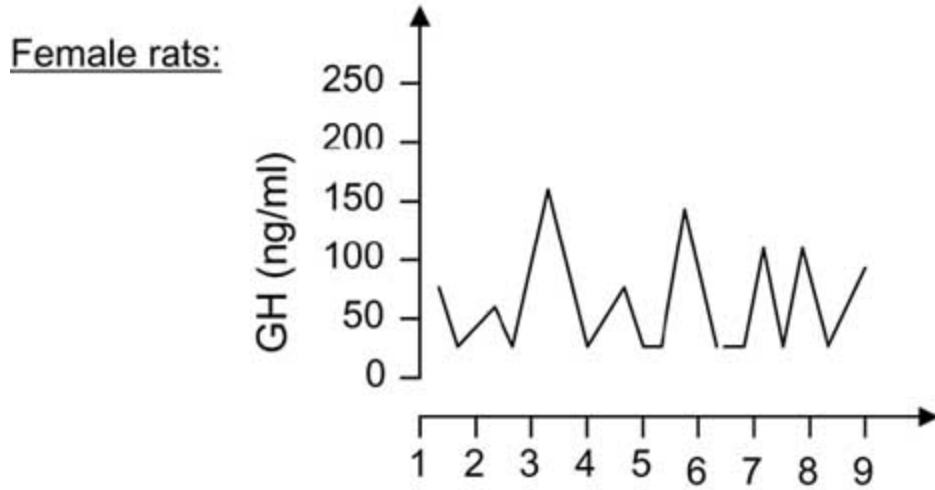

Time (hours)

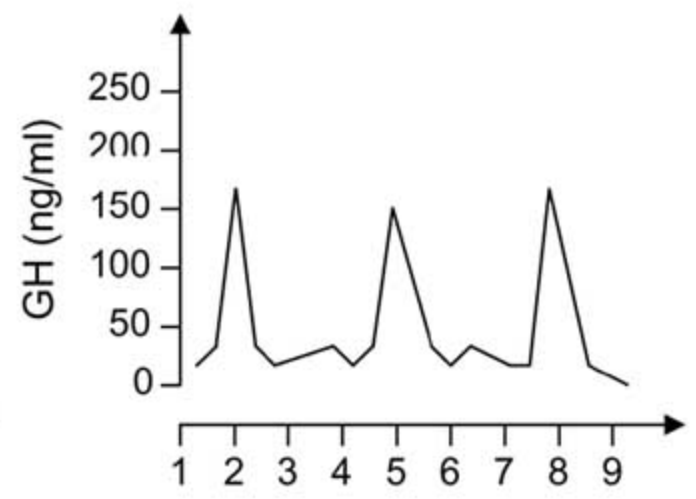

Time (hours)

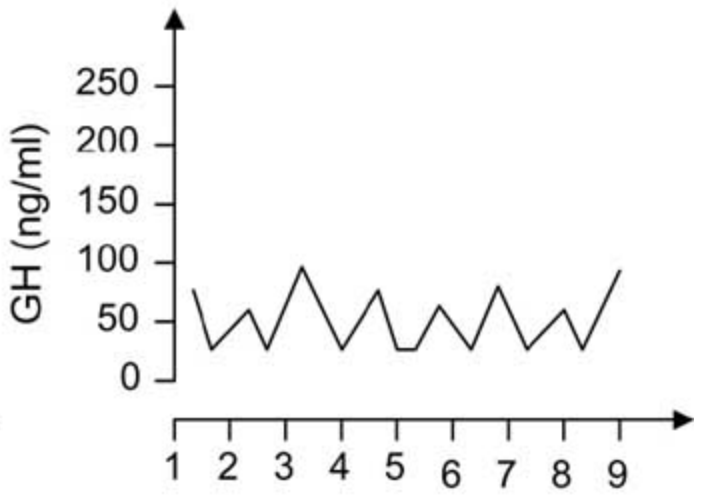

Time (hours)

Fig. (8). Schematic representation of the circulating growth hormone profiles from individual, undisturbed, catheterised young (3month-old) and senescent (24-month-old) male (upper panel) and female (lower panel) rats (adapted from [44]). 


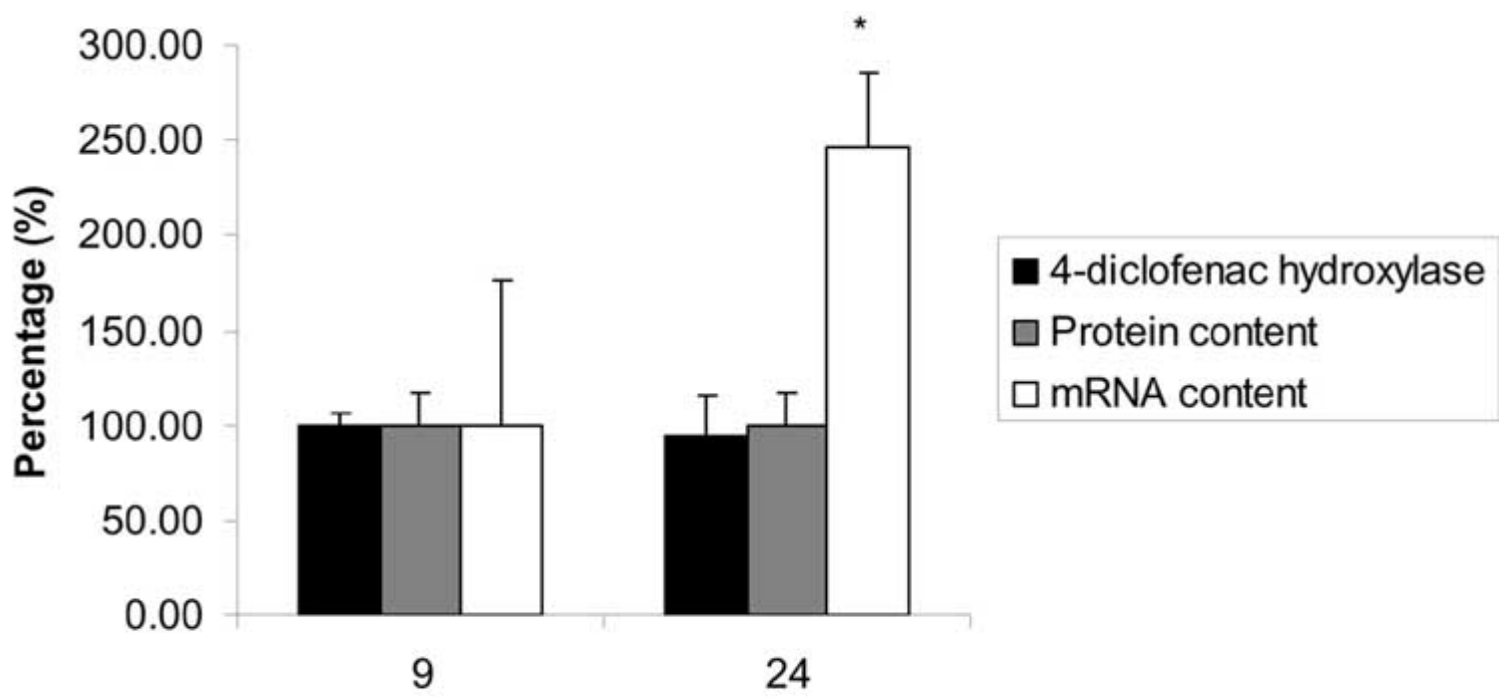

\section{Months}

Fig. (9). CYP2C6-mediated diclofenac hydroxylation, CYP2C6 protein content and mRNA level in the liver of adult and senescent male rats. CYP2C6 activity was measured in liver microsomes. 100\% of CYP2C6 activity corresponds to $0.7 \pm 0.04 \mathrm{nmol} / \mathrm{min} / \mathrm{mg}$ prot. The content of CYP2C6 protein was assessed by immunoblotting. $100 \%$ of protein content corresponds to $25.0 \pm 8.2$ optical density units units. The level of CYP2C6 mRNA was evaluated by RT-PCR. 100\% of mRNA level (normalized to $\beta$-actin mRNA levels) corresponds to $0.14 \pm 0.11$ arbitrary units. Values represent the mean \pm SEM of 6 rats.

panel), three changes in $\mathrm{GH}$ secretion profile can be noted in male rats of 24 months: 1) pulses with lower $(-30 \%)$ amplitudes; 2) increased number of pulses resulting in shorter $(\sim 15 \%)$ interpulse periods; and 3$)$ elevated nadirs due to a continuous presence of $\mathrm{GH}$ in the circulation in senescent rats, that is $15 \mathrm{ng} / \mathrm{ml}$ in senescent versus undetectable levels in adult rats [43, 68]. The demasculinization and feminization of CYP450 in the liver of senescent rats are caused by the loss of the GH-off period due to a continuous secretion of just nominal levels of the hormone [43]. Indeed, normal male-like expression levels of CYP2C11 and CYP3A2 are absolutely dependent on the GH free interpulse period whereas the expression of the female specific CYP2C12 is dependent on a continuous $\mathrm{GH}$ secretion.

On the other hand, the expression of sex-predominant CYPs is maintained in the liver of senescent rats suggesting a lower sensitivity to changes in the GH secretion profile than sex-specific CYPs. For example, in agreement with a previous report demonstrating no age-associated change in the basal level of CYP2C6 mRNA and CYP3A23 [69], both the activity and the expression of CYP2C6 as well as the mRNA levels of CYP3A18 and CYP3A23 remained constant from 9 to 24 months (Figs. 9 and 10).

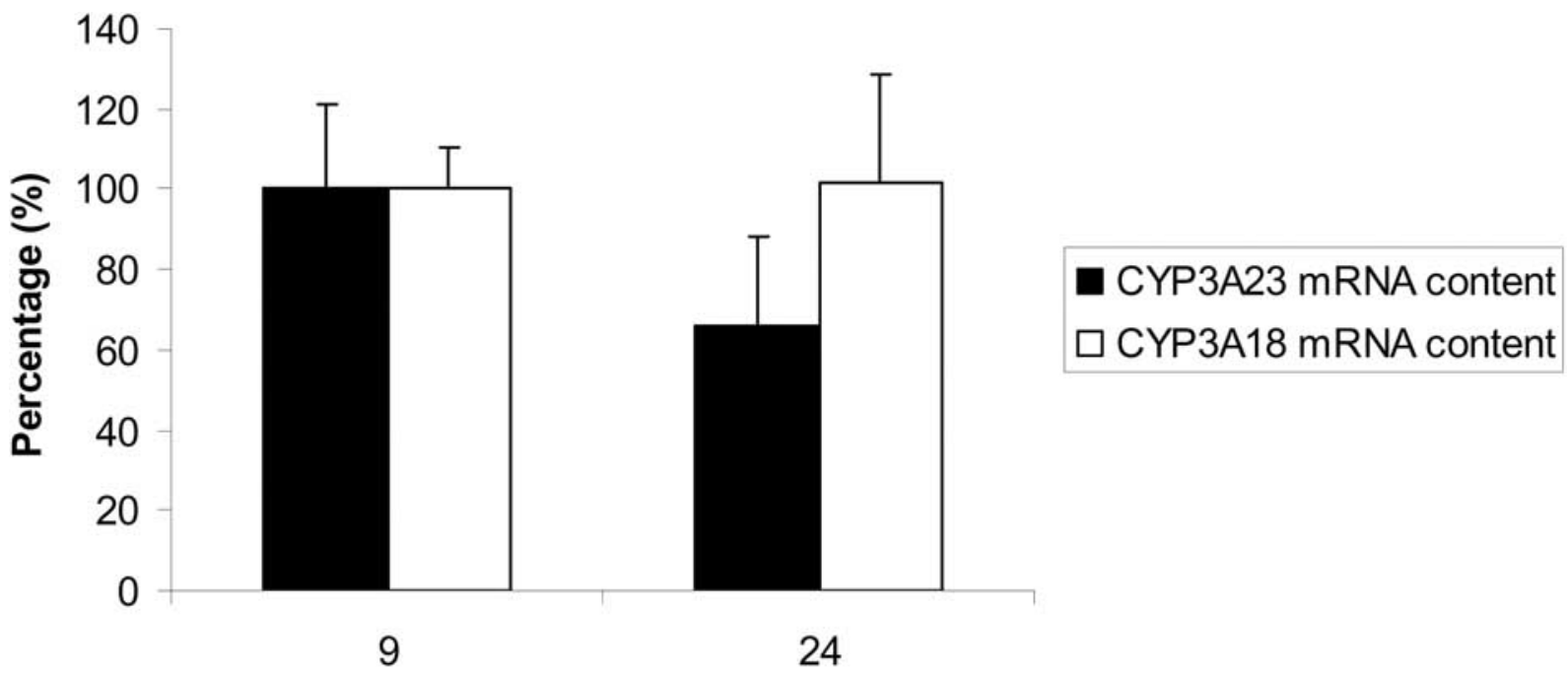

Age (months)

Fig. (10). CYP3A23 (left panel) and CYP3A18 (right panel) mRNA levels in the liver of adult and senescent male rats. The levels of CYP3A23 and CYP3A18 mRNA were evaluated by RT-PCR. Values were expressed as arbitrary units obtained by densitometry and after normalization to $\beta$-actin mRNA expression levels. Values represent the mean \pm SEM of 6 rats. 
In female rats of 24 months, changes in $\mathrm{GH}$ secretion can also be observed (Fig. 8, lower panel): GH secretion results in fewer pulses with lower amplitudes $(\sim 25 \%)$ resulting in longer trough periods than in the younger females [43]. However, these changes have been shown to have little impact on CYP expression in female senescent rats. Indeed, it has been shown that senescent female Fisher rats exhibited a small suppression in CYP2C6 and CYP2C12 expression [43].

\section{EFFECT OF AGEING ON CYP INDUCTION}

\section{a. Induction of CYPs}

A particular feature of some of the CYP genes is their dramatic ability to be induced, especially in the liver, by endogenous as well as structurally diverse foreign compounds. The induction can be defined as the increase in the amount and activity of drug metabolizing enzymes.

The scheme in (Fig. 11), shows that the mechanisms of induction are quite diverse. Although induction is mainly mediated through transcriptional mechanisms, other mechanisms such as stabilization of enzymes have also been reported, for example in the case of CYP2E1 induction.

Most rodent and human genes belonging to families CYPs 1-4 can be transcriptionally activated by foreign chemicals through one of four receptor-dependent mechanisms. These mechanisms can be mediated by the cytosolic receptor AhR (Aromatic hydrocarbon receptor) or by nuclear orphan receptors: CAR (Constitutive Androstane
Receptor), PXR (Pregnane X receptor) or PPAR $\alpha$ (Peroxisome proliferator-activated receptor) [70].

Regarding the mechanism of enzyme stabilisation, the induction of CYP2E1 by acetone or ethanol increases the half-life of CYP2E1 enzymes from 7 hours to 37 hours. The mechanism of induction involves a protection of CYP2E1 by the ligand (acetone or ethanol) against its degradation [71,72]. Indeed, degradation of CYP2E1 involves a phosphorylation at the serine-129 position which is followed by the loss of haem and the degradation by the proteasome system. It has been shown that the binding of ethanol or acetone to CYP2E1 blocks serine phosphorylation rendering its degradation impossible [73]. On the other hand, an increase of both CYP2E1 protein and mRNA levels are observed in diabetic rats. The nuclear Run on transcription analysis showed that this mRNA increase is not due to transcriptional activation but it is due to a specific stabilization of the CYP2E1 mRNA [71]. Furthermore, the induction of CYP2E1 by isoniazid is accompanied by an increase in CYP2E1 protein content but not in mRNA, and is completely blocked by pre-treatment of cycloheximide or sodium fluoride, inhibitors of mRNA translation. These data suggest that CYP2E1 induction by isoniazid is due to activation of CYP2E1 mRNA translation [74].

\section{b. Effect of Ageing on the Capacity of Cytochrome P450 Enzymes to be Induced}

In humans, the effect of age on induction is still unclear $[75,76]$. In rats, early studies are also conflicting and

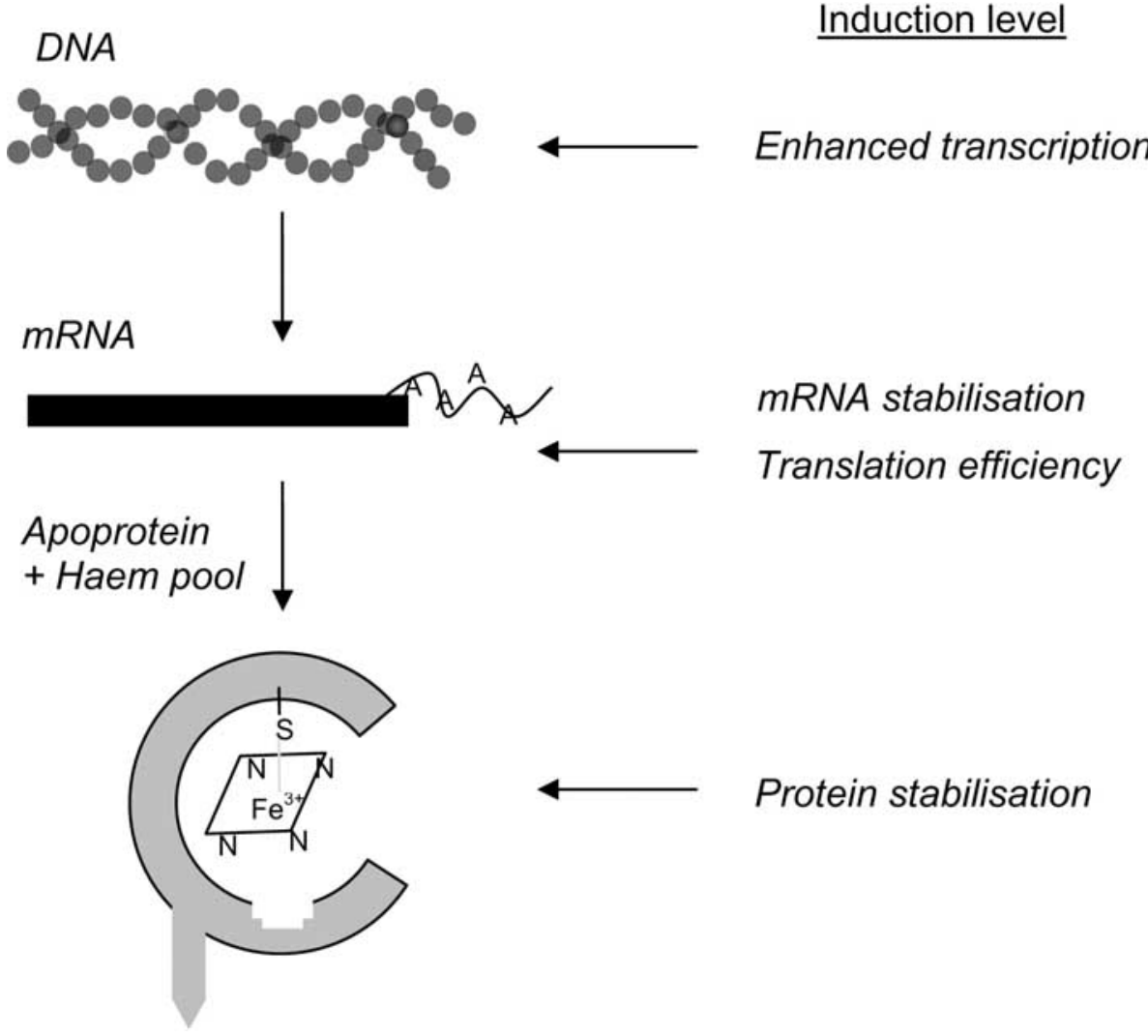

Fig. (11). Schematic representation showing the various levels of induction of cytochrome P450 enzymes. 


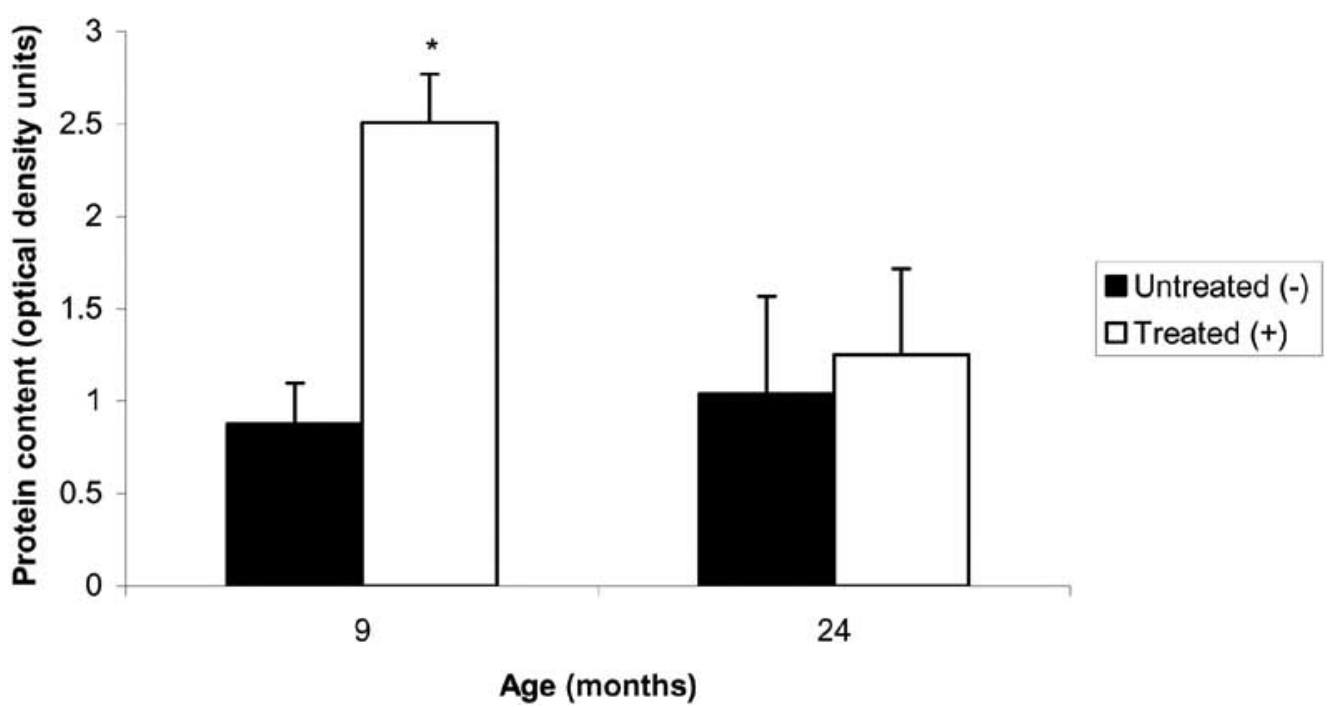

Fig. (12). CYP3A23 apoprotein induction by dexamethasone in rat liver slices prepared from rats of 9 and 24 months. Representative Western blots showing levels of CYP3A23 in untreated (-) and dexamethasone-treated (+) liver slices of rats of 9 and 24 months are presented. CYP3A23 content in the blots was measured by densitometry and the results are expressed as optical density units. Values represent the mean \pm S.E.M of 4 rats. $(*) \mathrm{p}<0.05$ as compared to untreated slices.

reported either a decrease [39,77-79] or no change [80] in the extent of monooxygenase induction by several agents.

For example, phenobarbital mediated induction has been shown to be either decreased [79] or not affected [69] with ageing. On the other hand, dexamethasone-mediated induction has been shown to be strongly decreased with ageing [50,81,82]. Indeed, the transcriptional induction of CYP3A23 by dexamethasone is followed by a significant increase of about 2-fold in CYP3A23 protein in liver slices of adult rats but a strong decrease in the induction was observed in senescent rats (Fig. 12). This loss in capacity of induction is in agreement with in vivo studies on various types of rat liver CYPs when administering phenobarbital $[81,82]$.

Although the induction of CYP3A23 seems to proceed through the heterodimerization of pregnane $\mathrm{X}$ receptor (PXR) with the retinoid X receptor (RXR) [83], we did not observe an age-related change in RXR or PXR mRNA levels in senescent rats (Fig. 13). Moreover, in addition to PXR/RXR, other nuclear receptors including COUP-TF and $\mathrm{HNF} 4 \alpha$ are required to get a full induction response [83]. Although the COUP-TF1 protein content did not change in senescent male rats as compared to adult rats, a strong decrease of the amount of $\mathrm{HNF} 4 \alpha$ protein was observed

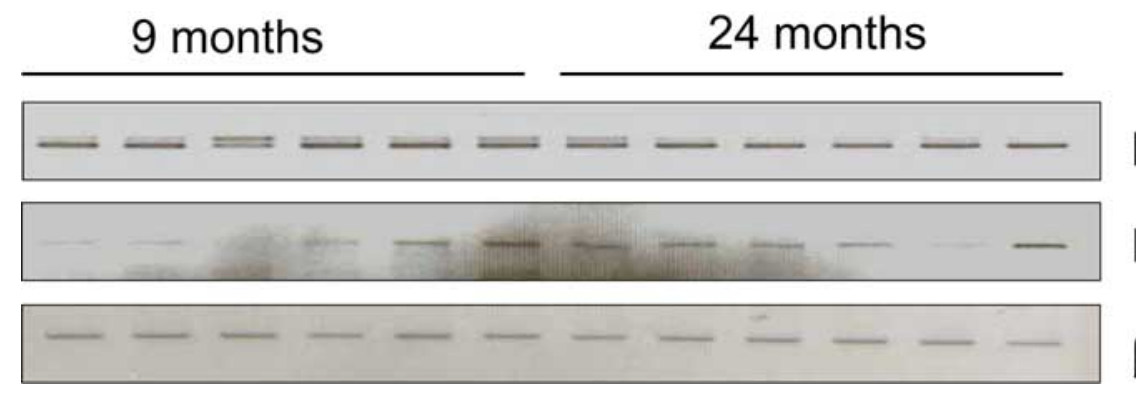

\section{4 months}

(Fig. 14). As previously reported [46], it can be suggested that the decreased ability of CYP3A23 to be induced by dexamethasone may be due to a decreased of HNF4 $\alpha$ DNA binding activity.

\section{CONCLUSION}

Although studies in rats clearly show that ageing impairs drug biotransformation, the underlying intracellular mechanisms are not yet understood [39,40-43,45-47,50]. Age related alterations in the activity of drug metabolising enzymes in humans may have important clinical consequences by affecting both drug efficacy and toxicity. Studies on the effect of ageing on drug metabolism carried out in rats [30,46] raise, therefore, an obvious question: "Can we extrapolate the age-related effect on the activity of drug metabolizing enzymes from rats to humans?" Unfortunately, the answer is unknown to date. However, sex differences in CYP-catalysed drug metabolism are also well established in humans. With certain drugs like caffeine $[84,85]$, shorter half-lives associated with greater clearance rates, are seen in men, while with other drugs women show higher rates of metabolism than men: e.g. the metabolic elimination rate of erythromycin is 2 -fold faster in women compared to men [86].

\section{PXR}

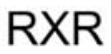

\section{$\beta$-actin}

Fig. (13). PXR and RXR mRNA levels in the liver of adult and senescent rats. The levels of PXR and RXR mRNA levels were evaluated by RT-PCR. 


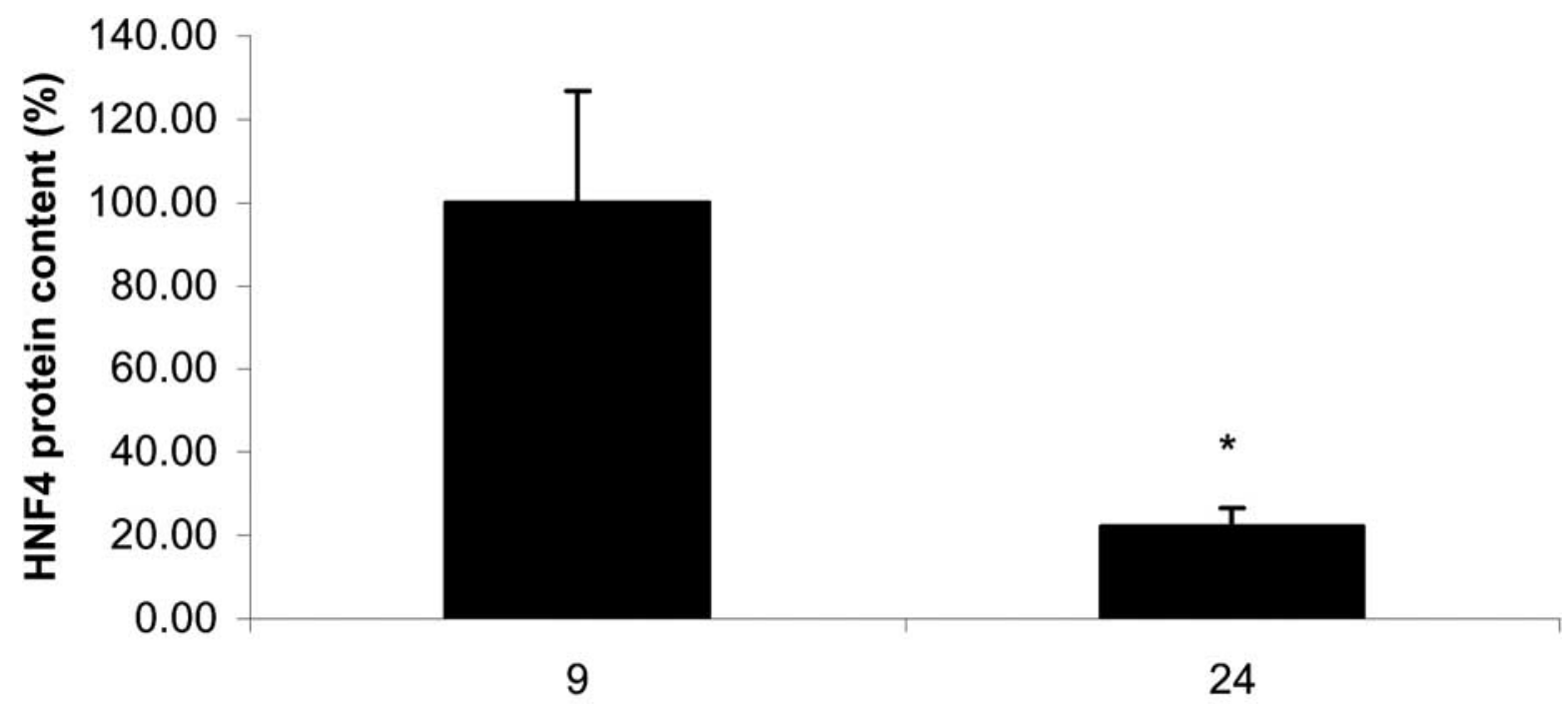

\section{Age (months)}

Fig. (14). HNF4 $\alpha$ protein content in the liver of adult and senescent rats. The amount of HNF4 $\alpha$ proteins was determined by Western blots. $100 \%$ of protein content corresponds to 4.4 optical density units. Values represent the mean \pm S.E.M of 6 rats. $(*)$ p $<0.05$ as compared to animals 9 months old.

Moreover, the likely relevance to humans of the general features of the GH-mediated CYP regulation is suggested by several facts. First, significant GH secretory pattern differences between males and females are seen in humans, although they are much less dramatic than those that occur in rodents [87]. Second, protein content of several human CYPs has been shown to be different in men and women. For instance, CYP3A4, the most abundant human liver CYP which accounts for up to 50\% of oxidative drug metabolism, has a $\sim 2$-fold higher expression in women as compared to men [56]. Third, several clinical studies investigating whether $\mathrm{GH}$ regulate human hepatic CYP activities, have shown that GH treatment can alter P450dependent drug metabolism in humans. For example, temporal patterns of $\mathrm{GH}$ administration given to $\mathrm{GH}$ deficient male and female patients have shown that CYP1A2 activity is down regulated by pulsatile $\mathrm{GH}$ treatment and CYP3A4 activity is increased more effectively by a continuous GH treatment [88]. Although the experimental model utilized is quite different from the physiological in vivo conditions, the $\mathrm{GH}$ responsiveness of some human CYPs has also been shown in human hepatocytes. For example, CYP3A4 is induced or maintained by continuous GH treatment $[89,90]$ but is suppressed by intermittent GH treatment [89].

In conclusion, sex differences in P450-dependent drug metabolism and $\mathrm{GH}$ regulation also occur in humans, and are regarded as clinically relevant determinants of human sex differences in drug efficacy and toxicity [91,92].

Since changes in the secretion of GH during ageing have also been reported in humans [93], studies on the regulation of the sex-dependent rat $\mathrm{P} 450$ enzymes by $\mathrm{GH}$ are of importance for understanding the regulation of human P450catalyzed drug metabolism.

Interindividual variability in drug metabolism is now recognized as an important factor in the age- dependent differences in pharmacokinetics and idiosyncratic drug toxicities seen in the clinic $[94,95]$ as well as by the U.S. FDA (www.fda.gov/cber/gdens/popharm.pdf).

Since geriatric patients receive a disproportionately high number of drugs and in addition very often take multiple medications (polypharmacy), pharmacotherapy in the elderly is a major challenge both for health professionals and for the social security system. A better understanding of the underlying mechanisms of age-related changes on the activity of drug metabolism enzymes is of utmost importance to improve pharmacotherapy and, in turn, increase efficacy and decrease toxicity of treatment in the elderly.

\section{REFERENCES}

[1] Anderson, G.; Kerluke K. J. Clin. Epidemiol., 1996, 49, 929.

[2] Jorgensen, T.; Johansson, S.; Kennerfalk, A.; Wallander, M.A.; Svardsudd, K. Ann. Pharmacother., 2001, 35, 1004.

[3] Kennerfalk, A.; Ruigomez, A.; Wallander, M.A.; Wilhelmsen, L.; Johansson, S. Ann. Pharmacother., 2002, 36, 797.

[4] McLean, A.J.; Le Couteur, D.G. Pharmacol. Rev., 2004, 56, 163.

[5] Hurwitz, N. Br. Med. J., 1969, $1,536$.

[6] Carbonin, P.; Pahor, M.; Bernabei, R.; Sgadari, A. J. Am. Geriatr. Soc., 1991, 39, 1093.

[7] $\quad \overline{B o r d e t, ~ R . ; ~ G a u t i e r, ~ S . ; ~ L e ~ L o u e t, ~ H . ; ~ D u p u i s, ~ B . ; ~ C a r o n, ~ J . ~ E u r . ~ J . ~}$ Clin. Pharmacol., 2001, 56, 935.

[8] Roughead, E.E.; Gilbert, A.L., Primrose, J.G.; Sansom, L.N. Med. J. Aust., 1997, 168, 405.

[9] Ebbesen, J.; Buajordet, I.; Erikssen, J.; Brors, O.; Hilberg, T.; Svaar, H.; Sandvik, L. Arch. Intern. Med., 2001, 161, 2317.

[10] Schmucker, D.L. Drugs Aging, 2001, 18, 837.

[11] Jacobzone, S. Health Aff., 2000, 19, 213.

[12] Watts, J. Lancet, 2001, 358, 731.

[13] Testa, B. The metabolism of drugs and other xenobiotics: Biochemistry of redox reactions. Ed Bernard Testa and John Caldwell, Academic Press, London, 1995.

[14] Hedlund, E.; Gustafsson, J.A.; Warner, M. Curr. Drug Metab., 2001, 2, 245.

[15] Jefcoate, C.R. (Ed) In Advances in Molecular and Cell Biology, vol.14 pp. 1-379, JAI Press, Greenwich, CT, 1996.

[16] Guengerich, F.P. Chem. Res. Toxicol., 2001, 14, 611. 
[17] Masoro, E.J.; Austad, S.N. Handbook of the biology of aging, (6th edition). Academic Press, San Diego, CA, 2006.

[18] Dodds, C. Pharmacol. Ther., 1995, 66, 369.

[19] Espínola, E.B.; Oliveira, M.G.M.; Carlini, E.A. Pharmacol. Biochem. Behav., 1999, 62, 419.

[20] Balducci, L. Eur. J. Cancer., 2000, 36, 1741.

[21] Smorenburg, C.H.; ten Tije, A.J.; Verweij, J.; Bontenbal, M.; Mross, M.; van Zomeren, D.M.; Seynaeve, C.; Sparreboom, A. Eur. J. Cancer, 2003, 39, 196.

[22] Durnas, C.; Voi, C.M.; Cusack, B.J. Clin. Pharmacokinet., 1990, $19,359$.

[23] Sotaniemi, E. A.; Arranto, A.J.; Pelkonen, O.; Pasanen, M. Clin. Pharmacol. Ther., 1997, 61, 331.

[24] Turnheim, K. Drugs Aging, 1998, 13, 357.

[25] Cusack, B.J. Am. J. Geriat. Pharmacother., 2004, $2,1$.

[26] Wynne, H.A.; Cope, L.H.; Mutch, E.; Rawlins, M.D.; Woodhouse, K.W.; James, O.F. Hepatology, 1989, 9, 297.

[27] Kinirions, M.T. Crome, P. Clin. Pharmacokinet., 1997, 33, 302.

[28] Schmucker, D.L. J. Gerontol. A Biol. Sci. Med. Sci., 1998, 53, B315.

[29] Cotreau, M.M.; Stonis, L.; Strahs, A.; Schwertschlag, U.S. Biopharm. Drug. Dispos., 2004, 25, 291.

[30] Schmucker, D.L.; Woodhouse, K.W.; Wang, R.K.; Wynne, H.; James, O.F.; McManus, M.; Kremers, P. Clin. Pharmacol. Ther., 1990, 48,365 .

[31] Shimada, T.; Yamazaki, H.; Mimura, M.; Inui, Y.; Guenguerich, F.P.J. Pharmacol. Exp. Ther., 1994, 270, 414.

[32] George, J.; Byth. K.; Farrell, G.C. Biochem. Pharmacol., 1995, $50,727$.

[33] Kinirions, M.T.; O’Mahoney, M.S. Br. J. Clin. Pharmacol., 2004, 57,540 .

[34] $\overline{B a c h, ~ B . ; ~ H a n s e n, ~ J . M . ; ~ J P, ~ R a s m u s s e n, ~ S . N . ; ~ S k o v s t e d, ~ L . ~ C l i n . ~}$ Pharmacokinet., 1981, 6, 389.

[35] Belpaire, F.M.; de Smet, F.; Vynckier, L.J.; Vermeulen, A.M.; Rosseel, M.T.; Bogaert, M.G.; Chauvelot-Moachon, L. J. Pharmacol. Exp. Ther., 1990, 254, 116.

[36] Hammerlein, A.; Derendorf, H.; Lowenthal, D.T. Clin. Pharmacokinet., 1998, 35, 49.

[37] Watkins, P.B.; Murray, S.A.; Winkelman, L.G.; Heuman, D.M.; Wrighton, S.A.; Guzelian, P.S. J. Clin. Invest., 1989, 83, 688.

[38] Le Couteur, D.G.; McLean, A.J. Clin. Pharmacokinet., 1998, 34, 359.

[39] Tanaka, E. J. Clin. Pharm. Ther., 1998, 23, 247.

[40] Kato, R.; Tanaka, A. J. Biochem., 1968, 63, 406.

[41] Kamataki, T.; Maeda, K.; Shimada, M.; Kitani, K.; Kitani, K., Nagai, T., Kato, R. J. Pharmacol. Exp. Ther., 1985, 233, 222.

[42] Morgan, E.T.; MacGeoch, C.; Gustafsson, J.A. J. Biol. Chem., 1985, 260, 11895 .

[43] Imaoka, S.; Fujita, S.; Funae, Y. Biochim. Biophys. Acta, 1991, 1097, 187.

[44] Dhir, R.N.; Shapiro, B.H. Proc. Natl. Acad. Sci. USA, 2003, 100, 15224.

[45] Warrington, J.S.; Court, M.H.; Greenblatt, D.J.; von Moltke L.L. J. Pharm. Pharmacol., 2004, 56, 819.

[46] Wauthier, V.; Verbeeck, R.K.; Buc Calderon, P. Arch. Toxicol., 2004, 78, 131.

[47] Wauthier, V.; Verbeeck, R.K.; Buc Calderon, P. Exp. Gerontol., 2006, 41,846

[48] Wauthier, V.; Schenten, V.; Verbeeck, R.K.; Buc Calderon, P. Life Sci., 2006, 79, 1913.

[49] Warrington, J.S.; Greenblatt, D.J.; von Moltke, L.L. J. Pharmacol. Exp. Ther., 2004, 309, 720.

[50] Schmucker, D.L.; Wang, R.K. Mech. Ageing Dev., 1983, 21, 137.

[51] Wauthier, V.; Verbeeck, R.K.; Buc Calderon, P. Toxicol. In vitro, 2004, 18,879 .

[52] Ueno, T.; Gonzalez, F.J. Mol. Cell Biol., 1990, 10, 4495

[53] Cheung, C.; Akiyama, T.E.; Kudo, G.; Gonzalez, F.J. Biochem. Pharmacol., 2003, 66, 2011.

[54] Shapiro, B.H.; Agrawal, A.K.; Pampori, N.A. Int. J. Biochem. Cell. Biol., 1995, 27, 9.

[55] Noshiro, M.; Negishi, M. J. Biol. Chem., 1986, 261, 15923.
[56] Lamba, V.; Lamba, J.; Yasuda, K.; Strom, S.; Davila, J.; Hancock, M.L.; Fackenthal, J.D.; Rogan, P.K.; Ring, B.; Wrigton, S.A.; Schuetz E.G. J. Pharmacol. Exp. Ther., 2003, 307, 906.

[57] Wolbold, R.; Klein, K.; Burk, O.; Nussler, A.K., Neuhaus, P.; Eichelbaum, M.; Schwab, M.; Zanger, U.M. Hepatology, 2003, 38, 978 .

[58] Jansson, J.O.; Eden, S.; Isaksson, O. Endocr Rev., 1985, 6, 128.

[59] Waxman, D.J.; Pampori, N.A.; Ram, P.A.; Agrawal A.K.; Shapiro B.H. Proc. Natl. Acad. Sci. USA, 1991, 88, 6868.

[60] Legraverend, C.; Mode, A.; Westin, S.; Strom, A.; Eguchi, H.; Zaphiropoulos, P.G.; Gustafsson, J.A. Mol. Endocrinol., 1992, 6, 259.

[61] Sundseth, S.S.; Alberta, J.A.; Waxman, D.J. J. Biol. Chem., 1992, 267, 3907.

[62] Jansson, J.O.; Frohman, L.A. Endocrinology, 1987, 121, 1417.

[63] Jansson, J.O.; Frohman, L.A. Endocrinology, 1987, 120, 1551.

[64] Waxman, D.J.; Dannan, G.A.; Guengerich, F.P. Biochemistry, 1985, 24, 4409.

[65] Thangavel, C.; Dworakowski, W.; Shapiro, B.H. Drug Metab. Dispos., 2006, 34, 410.

[66] Wiwi, C.A.; Waxman, D.J. Growth Factors, 2004, 22, 79.

[67] Eden, S. Endocrinology, 1979, 105, 555.

[68] Pampori, N.A.; Shapiro, B.H. Mol. Pharmacol., 1996, 50, 1148.

[69] Waxman, D.J.; Ram, P.A.; Pampori, N.A.; Shapiro, B.H. Mol. Pharmacol., 1995, 48, 790.

[70] Sonntag, W.E.; Steger, R.W.; Forman, L.J.; Meites, J. Endocrinology, 1980, 107, 1875.

[71] Agrawal, A.K.; Shapiro B.H. Drug Metab. Dispos., 2003, 31, 612.

[72] Waxman, D.J. Arch. Bioch. Biophys., 1999, 369, 11.

[73] Song, B.J.; Matsunaga, T.; Hardwick, J.P.; Park, S.S.; Veech, R.L.; Yang, C.S.; Gelboin, H.V.; Gonzalez, F.J. Mol. Endocrinol., 1987, 1,542 .

[74] Eliasson, E.; Johansson, I.; Ingelman-Sundberg, M. Proc. Natl. Acad. Sci. USA, 1990, 87, 3225 .

[75] Bardag-Gorce, F.; Li, J.; French, B.A.; French, S.W. Free Radic. Biol. Med., 2002, 32, 17.

[76] Park, K.S.; Sohn, D.H.; Veech, R.L.; Song, B.J. Eur. J. Pharmacol., 1993, $248,7$.

[77] Twum-barima, Y.; Finnigan, T.; Habash, A.I.; Cape R.D.; Carruthers S.G. Br. J. Clin. Pharmacol., 1984, 17, 595.

[78] O'Malley, K.; Crooks, J.; Duke, E.; Stevenson, I.H. Br. Med. J., 1971, 3, 607.

[79] Birnbaum, L.; Baird, M. Exp. Gerontol., 1978, 13, 299.

[80] McMartin, D.; O'Connor, J.; Fasco, M.; Kaminsky, L. Toxicol. Appl. Pharmacol., 1980, 54, 411.

[81] Schmucker, D.L.; Wang, R.K. Mech. Ageing Dev., 1981, 15, 189.

[82] Kao, J.; Hudson, P. Biochem. Pharmacol., 1980, 29, 1191.

[83] Horbach, G.J.; van Asten, J.G.; van Bezooijen, C.F. Biochem. Pharmacol., 1990, 40, 529.

[84] Groen, K.; Breimer, D.D.; Jansen, E.J.; van Bezooijen, C.F. $J$. Pharmacol. Exp. Ther., 1994, 268, 531.

[85] Huss, J.M.; Kasper, C.B. Mol. Pharmacol., 2000, 58, 48.

[86] Relling, M.V.; Lin, J.S.; Ayers, G.D.; Evans, W.E. Clin. Pharmacol. Ther., 1992, 52, 643.

[87] Carrillo, J.A.; Benitez, J. Br. J. Clin. Pharmacol., 1996, 41, 605.

[88] MacGeoch, C.; Morgan, E.T.; Gustafsson, J.-A. Endocrinology, 1985, 117, 2085.

[89] Veldhuis, J.D.; Anderson, S.M.; Shah, N.; Bray, M.; Vick, T.; Gentili, A.; Mulligan, T.; Johnson, M.L.; Weltman, A.; Evans, W.S.; Iranmanesh, A. Growth Horm. IGF Res., 2001, 11, S25.

[90] Jaffe, C.A.; Turgeon, D.K.; Lown, K.; Demott-Friberg, R.; Watkins, P.B. Am. J. Physiol. Endocrinol. Metab., 2002, 283, E1008.

[91] Liddle, C.; Goodwin, B.J.; George, J.; Tapner, M.; Farrell, G.C. $J$. Clin. Endocrinol. Metab., 1998, 83, 2411.

[92] Dhir, R.N.; Dworakowski, W.; Tangavel, C.; Shapiro, B.H. J. Pharmacol. Exp. Ther., 2006, 316, 87.

[93] Cheung, N.W.; Liddle, C.; Coverdale, S.; Lou, J.C., Boyages, S.C. J. Clin. Endocrinol. Metab., 1996, 81, 1999.

[94] Thurmann, P.A.; Hompesch, B.C. Int. J. Clin. Pharmacol. Ther., 1998, 36, 586.

[95] Tanaka, E. J. Clin. Pharm. Ther., 1999, 24, 339. 